\title{
TU/e emonowne

\section{Experimental investigation of an atmospheric photoconductively switched high-voltage spark gap}

\section{Citation for published version (APA):}

Hendriks, J., Broks, B. H. P., Mullen, van der, J. J. A. M., \& Brussaard, G. J. H. (2005). Experimental investigation of an atmospheric photoconductively switched high-voltage spark gap. Journal of Applied Physics, 98(4), 043309-1/6. [043309]. https://doi.org/10.1063/1.2035315

DOI:

10.1063/1.2035315

Document status and date:

Published: 01/01/2005

\section{Document Version:}

Publisher's PDF, also known as Version of Record (includes final page, issue and volume numbers)

\section{Please check the document version of this publication:}

- A submitted manuscript is the version of the article upon submission and before peer-review. There can be important differences between the submitted version and the official published version of record. People interested in the research are advised to contact the author for the final version of the publication, or visit the $\mathrm{DOI}$ to the publisher's website.

- The final author version and the galley proof are versions of the publication after peer review.

- The final published version features the final layout of the paper including the volume, issue and page numbers.

Link to publication

\section{General rights}

Copyright and moral rights for the publications made accessible in the public portal are retained by the authors and/or other copyright owners and it is a condition of accessing publications that users recognise and abide by the legal requirements associated with these rights.

- Users may download and print one copy of any publication from the public portal for the purpose of private study or research.

- You may not further distribute the material or use it for any profit-making activity or commercial gain

- You may freely distribute the URL identifying the publication in the public portal.

If the publication is distributed under the terms of Article $25 \mathrm{fa}$ of the Dutch Copyright Act, indicated by the "Taverne" license above, please follow below link for the End User Agreement:

www.tue.nl/taverne

Take down policy

If you believe that this document breaches copyright please contact us at:

openaccess@tue.nl

providing details and we will investigate your claim. 


\title{
Experimental investigation of an atmospheric photoconductively switched high-voltage spark gap
}

\author{
J. Hendriks, ${ }^{\text {a) }}$ B. H. P. Broks, J. J. A. M. van der Mullen, and G. J. H. Brussaard \\ Center for Plasma Physics and Radiation Technology, Department of Applied Physics, \\ Eindhoven University of Technology, P.O. Box 513, 5600 MB Eindhoven, The Netherlands
}

(Received 19 May 2005; accepted 25 July 2005; published online 25 August 2005)

\begin{abstract}
We report on the experimental investigation of the photoconductively switched gas-filled spark gap. When the laser intensity of a femtosecond laser is high enough (around $10^{18} \mathrm{~W} \mathrm{~m}^{-2}$ ), a plasma can be created that spans the complete distance between the electrodes. The gas-filled spark gap is then closed on a femtosecond time scale, similar to photoconductive switching of a semiconductor switch. Stochastic breakdown processes, such as avalanche and streamer formation that cause the breakdown in laser triggered spark gaps, are passed over, which results in faster rise time and less jitter. Measurements of the switched pulses as a function of laser energy were performed in a 1-mm gap at an applied voltage of $4.5 \mathrm{kV}$. A clear transition from triggering to switching was measured with increased laser energy. Measurements of the output pulses with the gap filled with nitrogen at $1 \mathrm{~atm}$ showed results very similar to measurements in air in the same gap. In the switching regime, the amplitude of the switched pulse did not depend strongly on the laser energy. Measurements at lower applied voltages but with the same gap distance showed that it was possible to switch voltages as low as $10 \%$ of the self-breakdown voltage. At low applied voltages, a significant difference between the applied voltage and the output voltage is measured. A possible explanation is given based on the dynamic behavior of the laser-created plasma. The measured rise time and jitter of the switched pulses were both below the resolution of the measurement equipment, i.e., better than 100 and 15 ps, respectively. (C) 2005 American Institute of Physics. [DOI: 10.1063/1.2035315]
\end{abstract}

\section{INTRODUCTION}

High-voltage pulses are widely used in applications ranging from radar to extreme ultraviolet (EUV) sources and from nuclear fusion experiments to waste-water treatment. Ultrashort high-voltage pulses with picosecond rise time and time stability (jitter) can lead to even more applications. One of these applications is to couple picosecond high-voltage pulses into an antenna structure. This way, broadband highintensity terahertz radiation is created with intensities an order of magnitude higher than the common lasersemiconductor approach. Higher intensities make terahertz radiation more suitable as an alternative for $\mathrm{x}$-rays for medical and security purposes. ${ }^{1}$ Another interesting application will be in the field of bioelectrics. Ultrashort high-voltage pulses can be used to explore the influence on biological cells of higher field strengths and shorter pulses. ${ }^{2}$ Our own interest is to use ultrashort high-voltage pulses for making compact pulsed dc electron accelerators to create ultrashort electron bunches. ${ }^{3}$

High-voltage pulses below $1 \mathrm{kV}$ with rise time and jitter of the order of 1 ps can be made by laser-driven photoconductive switching. In those switches, a high-resistive semiconductor separates two electrodes. When a laser illuminates the semiconductor, free electrons are created and the semiconductor becomes conducting. If a full path between the electrodes is illuminated with sufficient intensity, the switch is closed. Motet et al. ${ }^{4}$ used GaAs and a femtosecond dye

\footnotetext{
${ }^{a)}$ Author to whom correspondence should be addressed; electronic mail: j.hendriks@tue.nl
}

laser to generate $825-\mathrm{V}$ pulses with 1.4-ps rise time. An important drawback of this method especially for high-power applications is the limited current that can be switched.

High-power, high-voltage pulses are commonly switched using gas-filled or liquid spark gap switches. The main reason for using such switches lies in their capability to recover from breakdown, which allows much higher currents to be switched. One of the main disadvantages of these switches is the timing of the output pulses. To reduce jitter in spark gaps a laser can be used to trigger the switch. The laser pulse is focused in the gap between the two electrodes or on one of the electrodes. This creates free electrons, which are accelerated in the gap by the applied electric field. The accelerated electrons cause additional ionization and after avalanche and streamer formation a conducting ( $\mathrm{arc}$ ) channel is formed between the electrodes. The initial stochastic process of avalanche and streamer formation limits the rise time and time jitter of the switched pulses. ${ }^{5}$ Since the first laser-triggered switching experiments in the early 1960s, a wide variety of spark gap geometries and laser types have been investigated. ${ }^{6}$ It turned out that focusing a laser axially through the conductor into the gap gave a better time stability of the switched pulse. Because the laser has already defined a path with some ionization along its entrance axis, the breakdown occurs faster and at a better defined time. The typical rise time and jitter of laser-triggered high-voltage pulses of the order of $1-500 \mathrm{kV}$ are in the subnanosecond regime. ${ }^{7,8}$ Luther et al. ${ }^{9}$ made pulses of $10 \mathrm{kV}$ with time jitter as low as $35 \mathrm{ps}$, using a femtosecond Ti:sapphire laser.

In a recent Letter ${ }^{10}$ we reported on experiments designed 


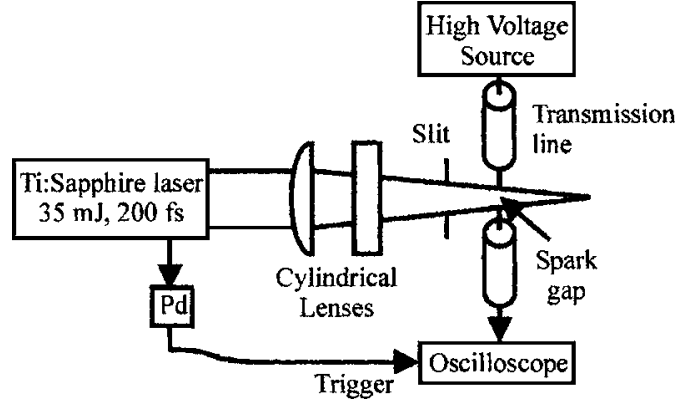

FIG. 1. Schematic overview of the experimental setup.

to combine these two switching regimes: photoconductive switching of semiconductors and laser triggering of a highvoltage spark gap. In these experiments we used a highintensity femtosecond Ti:sapphire laser in a gas-filled spark gap. But instead of focusing the laser to a point, we used two cylindrical lenses to create a slab of plasma between the electrodes. The idea was that, if the plasma completely fills the gap, the switch will be closed on a femtosecond time scale, similar to the photoconductive switching of the semiconductor switches. At the same time, with plasma as the conducting medium it will be possible to switch large currents without permanent damage to the switching medium. In these experiments we were able to switch pulses up to 4.5 $\mathrm{kV}$ with the measured rise time and jitter both limited by the time resolution of the measurement equipment, i.e., 100 and $15 \mathrm{ps}$, respectively.

In the present article we elaborate on the experiments reported in the Letter. In order to investigate this switching regime we varied a number of parameters, such as applied voltage, gas mixture, gap distance, and laser power. The results will illustrate other possibilities created by this switching method.

\section{EXPERIMENTAL SETUP}

Figure 1 gives a schematic overview of the experimental setup. It consists of the following parts: a high-voltage source connected to a spark gap, a Ti:sapphire laser system with cylindrical lenses to create the switching plasma, and diagnostics to analyze the switched high-voltage pulses.

\section{A. High-voltage spark gap setup}

Figure 2(a) depicts the electrical circuit of the spark gap setup. A 30-kV power supply (Lambda EMI 500A) was connected to a grounded 6-nF capacitor. We incorporated a highvoltage diode to prevent reflections back into the highvoltage (HV) source. The high-voltage source charged a $30-\mathrm{cm}$ coaxial transmission line through a $15-\mathrm{M} \Omega$ ceramic high-voltage resistor. The transmission line was interrupted by the spark gap. At the output side of the spark gap, the transmission line merged into a N-type cable connector. To prevent reflections in the measurement cable from interfering with the signal, a 2.8-m-long coaxial N-type cable was attached to this connector. This cable was terminated by a $13-\mathrm{fF}$ capacitor, connected directly to the $50-\Omega$ input of the oscilloscope. The oscilloscope used was a $1.5-\mathrm{GHz}, 8$ gi-

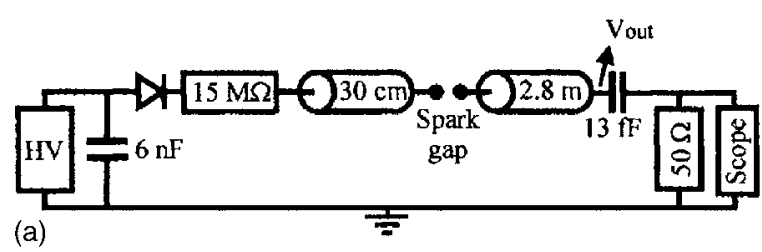

(b)

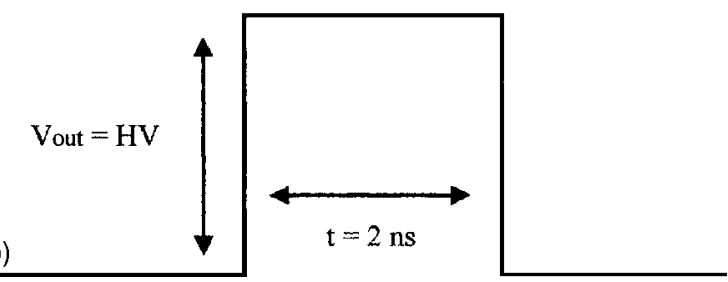

FIG. 2. (a) Electrical circuit of the high-voltage spark gap setup. (b) Ideal signal at the indicated position $\left(V_{\text {out }}\right)$.

gasample (GSa) Hewlett-Packard (HP) Infinium. In order to account for the capacitor and the load, the signal was digitally integrated and scaled to represent the signal at the end of the $2.8-\mathrm{m}$ transmission line.

If the spark gap acts as a perfect switch, with $0-\Omega$ resistance (when closed) and impedance matched to the transmission lines, the signal on the scope will be a square pulse [Fig. 2(b)]. When the switch is closed the applied voltage is divided over the two lines. The resulting pulse in the secondary line, therefore, is twice the length of the primary (charged line). The voltage in the second line is half the applied voltage. This switched pulse is reflected by the 13-fF capacitor, which leads to a doubling of the pulse at the point of reflection. The measured signals on the scope were converted to represent the pulse at the end of this secondary line. For an ideal switch, the output pulse amplitude is then equal to the applied voltage.

Figure 3 shows a cut view of the spark gap region. The inner conductor of the transmission line was made of copper, while the outer conductor was made of brass. They have diameters of 6 and $15 \mathrm{~mm}$, respectively, (characteristic impedance of $55 \Omega$ ). The replaceable tips of the inner conductors were made of copper-tungsten. The gap distance between the two inner conductors was set to $1 \mathrm{~mm}$, but can be varied. The gap was filled with atmospheric air. It is also possible to let nitrogen gas flow through the gap region (here, typically, with an overpressure of 0.2 bar). The ports for the switching laser and for diagnostic purposes were made to access the gap region.

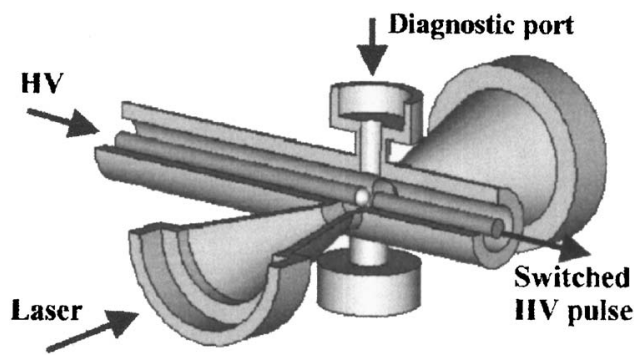

FIG. 3. Coaxial spark gap with ports for the switching laser and ports for diagnostic purposes. 


\section{B. Femtosecond Ti:sapphire laser system}

Compared with semiconductors, the photoconductive switching of a gas-filled spark gap requires far greater laser intensity. The intensity needs to be high enough throughout the gap, to create a plasma over the complete distance between the electrodes. For a gas-filled gap, this means that the intensity has to be above the threshold for tunneling ionization, around $10^{18} \mathrm{~W} \mathrm{~m}^{-2}$ for most gases. ${ }^{11,12} \mathrm{We}$ also require this ionization to occur on a time scale much smaller than the expected rise time. A high-power femtosecond Ti:sapphire laser fulfills both these criteria.

Our femtosecond Ti:sapphire laser system consists of three parts. First a mode-locked Ti:sapphire laser oscillator (Femtolasers $\mathrm{GmbH}$ ) produces broadband laser pulses with an energy of $5 \mathrm{~nJ}$ and a duration of $15 \mathrm{fs}$ at a central wavelength of $800 \mathrm{~nm}$. The repetition frequency is $75 \mathrm{MHz}$. These pulses were then amplified in the first chirped pulse amplifier (CPA). Here, a Ti:sapphire crystal was pumped by a $\mathrm{Nd}$ : yttrium lithium flouride (YLF) laser (B.M. industries) with an energy of $8 \mathrm{~mJ}(527 \mathrm{~nm})$ at a repetition rate of $1 \mathrm{kHz}$. After nine passes, this first CPA produced pulses of $1 \mathrm{~mJ}$ and $25 \mathrm{fs}(40 \mathrm{GW})$. A Pockel's cell defines the repetition rate at $10 \mathrm{~Hz}$. Part of the light was coupled out for other purposes while the remaining light was led into the second CPA. Here a Nd: yttrium aluminum garnet (YAG) laser (Thales SAGA 230/10) with a pulse energy of $1.25 \mathrm{~J}$ at $532 \mathrm{~nm}(10 \mathrm{~Hz})$ pumped another Ti:sapphire crystal. After five amplification passes, pulses of $35 \mathrm{~mJ}$ and $200 \mathrm{fs}(\sim 0.2 \mathrm{TW})$ at a repetition frequency of $10 \mathrm{~Hz}$ were produced. At this point the beam had a diameter of $7 \mathrm{~mm}$ (full width at half maximum). A small part of it was coupled out onto a photodiode. This signal was used to trigger the oscilloscope. The rest of the beam was led through a horizontal and a vertical cylindrical lens (focal distances of 150 and $200 \mathrm{~mm}$, respectively) to create a slab of plasma, spanning the complete distance between the electrodes. A slit was placed in front of the laser entrance port to prevent the edges of the laser pulse from hitting the electrodes.

The incoming laser beam is $7 \mathrm{~mm}$ in diameter (full width at half maximum). The horizontal cylindrical lens ( $f$ $=150 \mathrm{~mm}$ ) was located at $150 \mathrm{~mm}$ from the center of the gap and the vertical lens $(f=200 \mathrm{~mm})$ was located $186 \mathrm{~mm}$ from the center of the gap. The laser focus that creates the plasma in the spark gap was imaged on a charge-coupled device (CCD) camera and analyzed. The width of this focus was $949 \pm 6 \mu \mathrm{m}$ and its height was $20 \pm 3 \mu \mathrm{m}$ [both full width at half maximum (FWHM)]. At the maximum energy used (34 $\mathrm{mJ})$, the intensity in the center of the gap is almost $10^{19} \mathrm{~W} \mathrm{~m}^{-2}$. At the maximum laser energy, the intensity over the entire length of the gap is above the threshold for tunneling ionization in air $\left(10^{18} \mathrm{~W} \mathrm{~m}^{-2}\right)$.

\section{RESULTS AND DISCUSSION}

Figure 4 shows output pulses that were switched with different laser energies. The applied voltage was $4.5 \mathrm{kV}$ (90\% of the self-breakdown voltage) and the spark gap distance was $1 \mathrm{~mm}$. The gap was filled with atmospheric air. The evolution of the pulses in order of increasing energy can

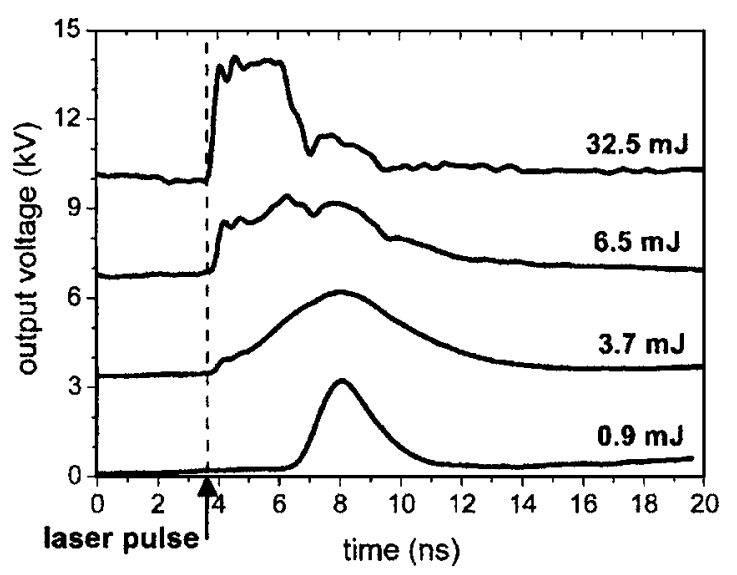

FIG. 4. Pulses switched at different laser energies $\left(V_{\text {app }}=4.5 \mathrm{kV}\right.$, gap $=1 \mathrm{~mm}$, and atmospheric air). The curves are offset for clarity. The arrival time of the switching laser pulse is indicated by the dashed line.

be understood as follows: At low energy (bottom curve) there is not enough laser energy available to sufficiently ionize the complete gap. The laser creates some ionizationmainly in the center of the gap and subsequently the stochastic processes of avalanche and streamer formation cause the actual breakdown of the gap. The time jitter is of the order of nanoseconds at this laser energy. Increasing the laser energy $(3.7 \mathrm{~mJ}$ in Fig. 4) results in a small voltage step at the beginning of the pulse, just after the arrival of the laser pulse. In this case, the laser energy is high enough to create a plasma connecting the two conductors. In this initial rise, the stochastic processes of avalanche and streamer formation are passed over and the time jitter is reduced to a level well below 100 ps (dedicated time-jitter measurements are presented below). However, due to the resistance of the initial plasma, only a small part of the pulse stored in the charged line is switched in this first step. The charged line discharges completely in 8-10 ns. When the laser energy is increased further $(6.5 \mathrm{~mJ})$, the resistance of the initial laser-created plasma is lower and a larger fraction of the pulse is switched immediately. In the upper curve $(32.5 \mathrm{~mJ})$ the laser energy is high enough to create a plasma with a resistance low enough to switch nearly the full charge. The pulse now has a rectangular shape and a width of $2 \mathrm{~ns}$ (determined by the length of the charged transmission line). A small pulse is visible behind the pulse, also with a width of 2 ns. This trailing pulse is likely to be caused by reflections on the interface between the transmission line and the plasma: When the laser-created plasma is formed, a traveling wave from the charged transmission line starts to propagate. Because the laser-created plasma is not matched to the charged inner conductor, reflections will occur at the interface. The reflected part of the pulse propagates in the opposite direction, reflects at the input resistance of the charged line, and returns at the spark gap 2 ns after the initial pulse.

These measurements of varying laser energy were also done in a flow of nitrogen gas with the same applied voltage and the same gap distance. A similar evolution of the switched pulse with increasing laser energy is visible.

The measurements in Fig. 4 suggest a transition from the classical triggered regime, in which the laser initiates a 

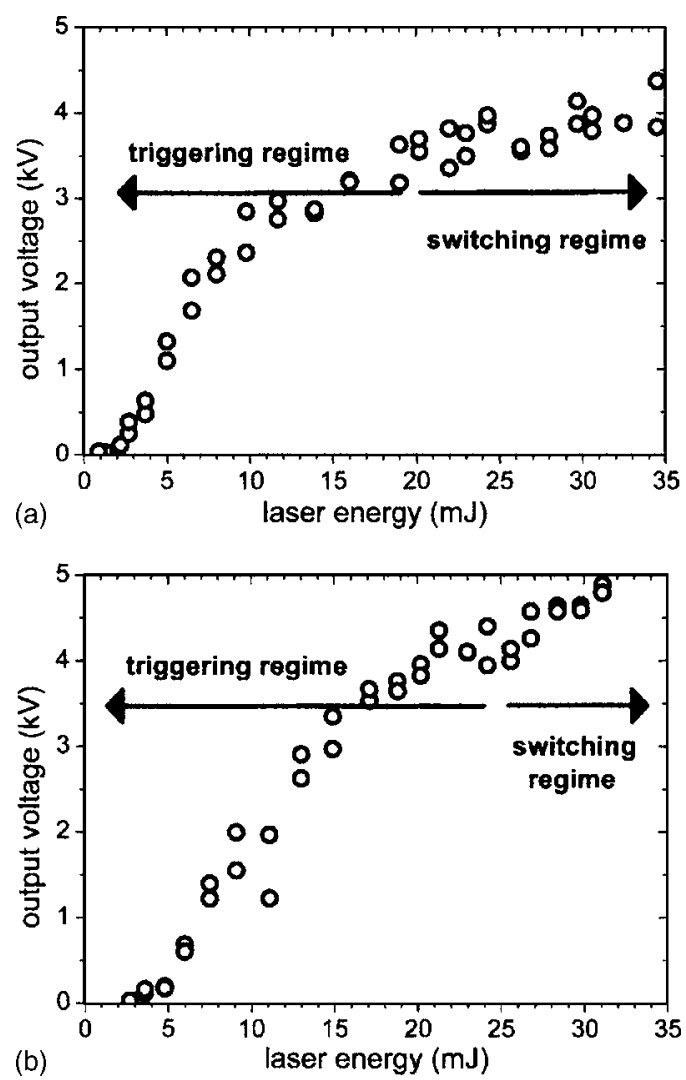

FIG. 5. Amplitude of the rising edge of the switched pulse in air (a) and nitrogen (b) as a function of the applied laser energy $\left(V_{\text {app }}=4.5 \mathrm{kV}\right.$ and gap $=1 \mathrm{~mm}$ ).

breakdown, to a switching regime where the stochastic processes are passed over and the full amplitude of the output pulse is reached within the first 100 ps (the time resolution of our measuring equipment). This interpretation is also supported if we plot the amplitude of the rising edge of the switched high-voltage pulse as a function of the laser pulse energy. These results are given in Fig. 5 for air [Fig. 5(a)] and nitrogen [Fig 5(b)]. The applied voltage was kept constant at $4.5 \mathrm{kV}$. Each data point is a single shot measurement. The variation in output voltage at a given setting (input voltage and laser energy) is caused by the method of measuring the output pulse. The capacitive measurement gives the time derivative of the pulse in the transmission line. Due to the fast onset of the pulse the integration of the capacitive signal relies from four to five data points. The error introduced by the limited sampling speed of the scope is estimated to be around $10 \%$ and can account for the variations in the output voltages of Fig. 5.

It can be seen in Fig. 5 that at low laser energy only a small part of the applied voltage is transmitted in the rising edge of the switched pulse. When the laser energy increases, the amplitude of the rising edge of the switched pulse increases until it approaches the value of the applied voltage. Further increase of the laser energy has little effect on the switched pulse. Figure 5 shows that there is indeed a transition between two regimes: the triggering regime, when there is not enough laser energy available to initially switch the full amplitude of the pulse, and the switching regime, where the applied laser energy is sufficient to reach the full ampli-

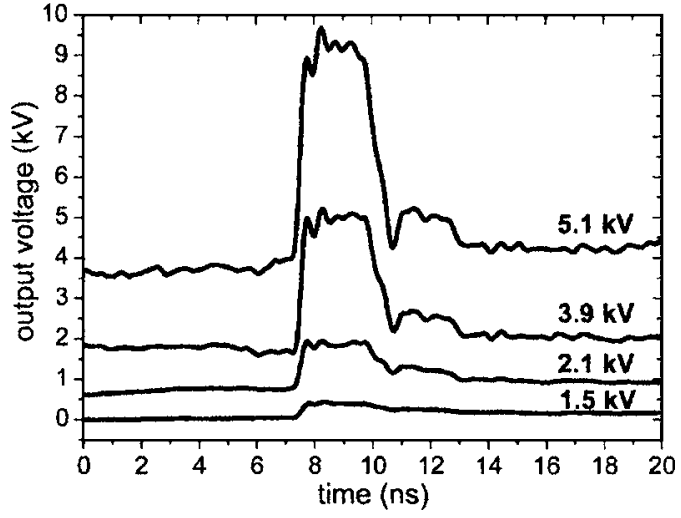

FIG. 6. Switched pulses of different applied voltages $\left(E_{\text {laser }}=34 \mathrm{~mJ}\right.$ and gap $=1 \mathrm{~mm}$ ) in atmospheric air. The measurements at different applied voltages are offset vertically for clarity.

tude in the rising edge of the pulse. The transition between these regimes is somewhat higher for nitrogen $(25 \mathrm{~mJ}$ for the settings used) than for air (around $20 \mathrm{~mJ}$ ).

If the pulses at high laser energy are switched photoconductively, similar to photoconductive switching of semiconductors, rather than triggered as in conventional spark gaps, it should be possible to switch pulses far below the selfbreakdown voltage of the spark gap. This greatly increases the applicability of gas-filled switches, since laser-triggered gas-filled spark gaps have a rather limited optimum operating range around $80 \%-90 \%$ of the self-breakdown voltage. To investigate this feature, we measured the output pulses at different applied voltages at a laser energy of $34 \mathrm{~mJ}$, i. e., in the saturated part of Fig. 5. The output pulses are shown in Fig. 6. The highest applied voltage $(5.1 \mathrm{kV})$ was just below the self-breakdown of the gap. Figure 6 shows that the sharp initial voltage rise and the pulse shape persist at lower voltages. These results also show that it is indeed possible to use this switch far below the self-breakdown voltage of the gap. The amplitude of the lowest output pulse in Fig. 6 is $0.5 \mathrm{kV}$, less than $10 \%$ of the self-breakdown voltage. Output voltages below $0.5 \mathrm{kV}$ were difficult to measure with good accuracy in the present setup due to the use of the capacitor to measure the pulse. Figure 7 gives the amplitude of the rising edge of the output pulse as a function of applied voltage. In the high laser-energy regime this is equal to the amplitude of the entire pulse (see Fig. 6). The measurements were performed in atmospheric air and nitrogen with a 1-mm gap and in air with a 0.35 -mm gap.

In all three experimental series, the laser energy was high enough to be in the switching regime, i. e., the saturated part of Fig. 5. The laser intensity was comparable in the 0.35 - and the 1-mm gaps. The energy of the laser was measured before the laser entrance port. For the smaller gap, the focusing lenses were kept in the same position, while the width of the slit at the laser entrance port was decreased to cut a larger part of the laser. The measurements at 1-mm gap distance in air and nitrogen both show that close to selfbreakdown $(\sim 5 \mathrm{kV})$ the output voltage equals the applied voltage. However, at voltages below $4 \mathrm{kV}$, a deviation from the dashed line, $V_{\text {appl }}=V_{\text {out }}$, occurs. There is a trend towards a threshold at approximately $1-\mathrm{kV}$ applied voltage. The mea- 


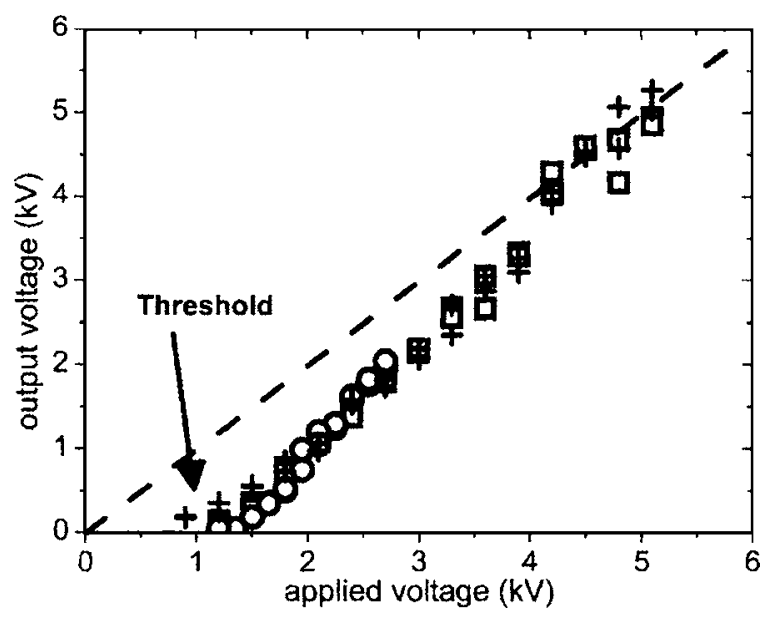

FIG. 7. Amplitude of the output voltage as a function of applied voltage at different experimental settings. $\square$ gap filled with air, gap distance $=1 \mathrm{~mm}$, and laser energy $=34.0 \mathrm{~mJ}$. $\bigcirc$ gap filled with air, gap distance $=0.35 \mathrm{~mm}$, and laser energy $=32.2 \mathrm{~mJ}$. + gap filled with $\mathrm{N}_{2}$, gap distance $=1 \mathrm{~mm}$, and laser energy $=28.6 \mathrm{~mJ}$.

surements done in a smaller gap filled with air (triangles in Fig. 7) show the same trend. In fact, the measurements at different settings all overlap, even though the self-breakdown voltage was approximately two times smaller in the $0.35-\mathrm{mm}$ gap than in the 1-mm gap.

From a practical point of view, the deviation from the line $V_{\text {appl }}=V_{\text {out }}$ and the threshold at approximately $1 \mathrm{kV}$ merely imply that at low voltage, in order to reach a certain output pulse, a slightly higher applied voltage must be used. However, a straightforward explanation of the results in Fig. 7 is not readily available. Comparison of the results in a $1-\mathrm{mm}$ gap to those in the $0.35-\mathrm{mm}$ gap shows that the important parameter is not so much the electric field in the gap, but rather the applied voltage. A possible explanation for the results can be given by looking at the initial laser-created plasma. We are not able to determine the ionization degree or electron temperature of the switching plasma. However, we can give a qualitative description of the behavior shown in Fig. 7 if we estimate the initial laser-induced ionization degree to be $1 \%$. This means that the electron density in the laser-created plasma is approximately $10^{23} \mathrm{~m}^{-3}$. The electron temperature for such a plasma will be $1-2 \mathrm{eV}$ (10\% of the ionization energy of most constituents). This weakly ionized plasma is dominated by electron-atom collisions and its electrical conductivity is given by Mitchner and Kruger. ${ }^{13}$ For the parameters chosen, this initial conductivity is of the order of $10^{3} \Omega^{-1} \mathrm{~m}^{-1}$. Thus, the initial resistance of the plasma is high $(\sim 500 \Omega)$ compared with the impedance of the transmission lines. At high voltages, the current through the plasma will create more ionization which lowers the impedance. This process takes place at time scales of the order of tens of picoseconds and cannot be resolved with our diagnostics. At low voltages the current is not high enough to create sufficient extra ionization and to lower the impedance of the plasma. The output voltage remains significantly lower than the applied voltage. This explanation suggests that photoconductive switching is possible even at low initial ionization $(1 \%)$, although the output voltage can be significantly

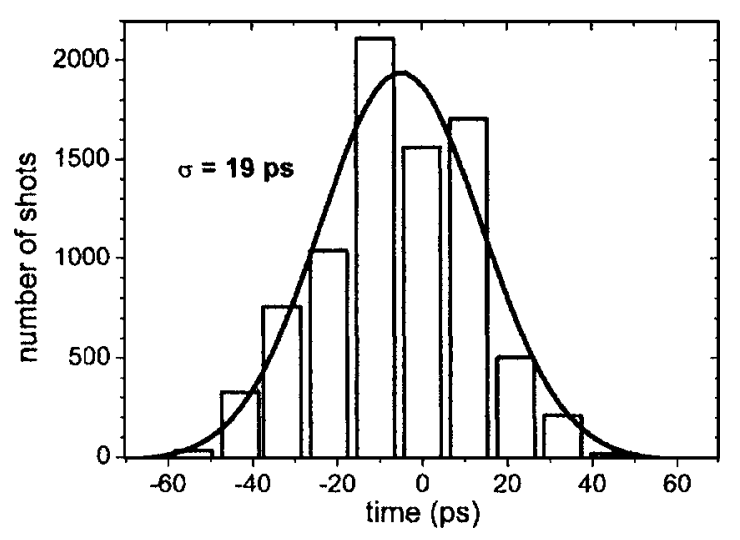

FIG. 8. Time-jitter distribution histograms measured at the initial voltage rise flank in the air-filled gap.

lower than the applied voltage. At higher laser intensities, this effect will be less, since the initial resistance of the laserproduced plasma will already be low compared with the 50 $-\Omega$ transmission line impedance.

Another important parameter of laser switching of high voltages is the time jitter of the switched pulses. To determine the jitter, the arrival-time variation of the switched pulses is measured for a large number of shots. The laser pulse is taken as the reference pulse. The arrival time is taken as the time at which the measured signal passes a preset level. A histogram with the time-of-arrival distribution is depicted in Fig. 8 for a measurement series of 15 minat $10-\mathrm{Hz}$ repetition frequency. The applied voltage was $4.5 \mathrm{kV}$ and the laser energy was $35 \mathrm{~mJ}$. The solid line is a Gaussian fit to the measured data. Measurements were done for both the airfilled gap and the nitrogen flow through the gap, both at a gap distance of $1 \mathrm{~mm}$. There was no significant difference in the measured time jitter for the two gases. The accuracy of the jitter measurements was limited by the time resolution of the oscilloscope $(1.5 \mathrm{GHz}$ and $8 \mathrm{GSa})$. To determine the resolution of the scope, the output of a pulse generator (Stanford Research Systems DG535) was split and applied to both the trigger and signal input of the scope. For a series of 15 minat $10-\mathrm{Hz}$ repetition frequency the measured time jitter was 12 ps. The measurements were also sensitive to amplitude variations in the (capacitively measured) switched pulse. In the present setup, we were not able to measure the time variation at a constant fraction of the amplitude. A variation of the amplitude shifts the time at which the edge of the switched pulse passed the preset measurement level. This way an amplitude variation of $10 \%$ resulted in 10-ps apparent time jitter. Together, the resolution of the scope and the amplitude variations in the switched pulse can account for the measured jitter of Fig. 8. The jitter induced by the switching process is therefore expected to be less than $10 \mathrm{ps}$.

\section{CONCLUSION}

We report an experimental investigation of the photoconductively switched gas-filled spark gap. At high enough laser intensities (around $10^{18} \mathrm{~W} \mathrm{~m}^{-2}$ ), the amplitude of the output pulse shows saturation with laser energy. In this regime, the switch operates more like a photoconductive semiconductor 
switch, rather than a conventionally triggered spark gap. The stochastic breakdown process of avalanche and streamer formation is passed over and does no longer limit the rise time and time jitter of the output pulses. Measurements with nitrogen in a 1-mm gap showed results very similar to measurements in air in the same gap. The switch was also operated far below the self-breakdown voltage. Reducing the gap distance had no significant influence on the output pulse shape. The insensitivity of the output pulse to these parameters implies that such a switch can have great potential in producing stable output pulses in a wide parameter range.

At low applied voltages (or, as it seems, low current through the gap) there is a significant difference between the applied voltage and the output voltage. A possible explanation was offered, based on the assumption that the initial laser-produced plasma was weakly ionized (1\% ionization degree). The conductivity of the plasma in that case depends on the current through the switch. At low applied voltage this current is insufficient to lower the resistance of the plasma below the $50-\Omega$ impedance of the transmission lines.

The measured rise time of the switched pulses was better than 100 ps and the time jitter was around 15 ps. Both rise time and jitter measurements were limited by the resolution of the measurement equipment.

\section{ACKNOWLEDGMENTS}

We would like to thank E. Rietman, A. Kemper, W. Kemper, and H. van Doorn for their technical support and W. J. M. Brok for the useful discussion. This research was funded by the Technology Foundation STW, applied science division of NWO and the technology program of the Ministry of Economic Affairs, the Royal Netherlands Academy of Arts and Sciences (KNAW), and the Foundation for Fundamental Research on Matter (FOM).

${ }^{1}$ C. Zandonella Nature (London) 424, 721 (2003).

${ }^{2}$ K. H. Schoenbach, S. Katsuki, R. H. Stark, E. S. Buescher, and S. J. Beebe, IEEE Trans. Plasma Sci. 30, 293 (2002).

${ }^{3}$ S. B. van der Geer, M. J. de Loos, G. J. H. Brussaard, O. J. Luiten, and M. J. van der Wiel, Proceedings of the Seventh European Particle Physics Conference Paris, France, June 3-7, 2002 (European Physical Society Interdivisional Group on Accelerators (EPS-IGA) and CERN). Printed at CERN, European Organization for Nuclear Research, European Laboratory for Particle Physics, Geneva, Switzerland, p. 989.

${ }^{4}$ T. Motet, J. Nees, S. Williamson, and G. Mourou, Appl. Phys. Lett. 59, 1455 (1991)

${ }^{5}$ J. M. Lehr, C. E. Baum, W. D. Prather, and R. J. Torres, in Fundamental Physical Considerations for Ultrafast Spark Gap Switching, Ultrawideband, Short Pulse Electromagnetics Vol. 4, edited by E. Heyman (Kluwer Academic/Plenum, New York, 1999), pp. 11-20.

${ }^{6}$ A. H. Guenther and J. R. Bettis, J. Phys. D 11, 1577 (1978).

${ }^{7}$ J. R. Woodworth, C. A. Frost, and T. A. Green, J. Appl. Phys. 53, 4734 (1982).

${ }^{8}$ J. R. Woodworth, P. J. Harris, Jr., L. C. Pitchford, and R. A. Hamil, J. Appl. Phys. 56, 1382 (1984).

${ }^{9}$ B. M. Luther, L. Furfaro, A. Klix, and J. J. Rocca, Appl. Phys. Lett. 79, 3248 (2001).

${ }^{10}$ G. J. H. Brussaard and J. Hendriks, Appl. Phys. Lett. 86, 081503 (2005).

${ }^{11}$ S. Augst, D. Strickland, D. D. Meyerhofer, S. L. Chin, and J. H. Eberly, Phys. Rev. Lett. 63, 2212 (1989).

${ }^{12}$ C. Guo, M. Li, J. P. Nibarger, and G. N. Gibson, Phys. Rev. A 58, R4271 (1998).

${ }^{13}$ M. Mitchner and C. H. Kruger, Partially Ionized Gases (Wiley, New York, 1973). 